\title{
Disease awareness as a barrier to health service admittance. An alternative healthcare model based on population needs
}

\author{
GUSTAVO H. MARIN ${ }^{1,2, A, ~ D, ~ E, ~ G, ~ P A B L O ~ V E T E R E ~}{ }^{1, B}$, LUPE MARIN $^{1, C, ~ D, ~ F, ~ L U C I A ~ G I A N G R E C O ~}{ }^{1, B}$, \\ ORCID ID: 0000-0002-6380-6453 \\ GLADYS GARCIA ${ }^{1, B}$, GINA MARIN ${ }^{1, C, ~ D, ~ F, ~ J U A N ~ A L C O N A D A-M A G L I A N O ~}{ }^{1, B}$, MARIA LAURA \\ FERRERO ${ }^{1, B}$, MARCELO BOURGEOIS ${ }^{1, B}$, MARIA GABRIELA MADONIA ${ }^{1,}$, VIRGINIA MORAN $^{1, B}$, \\ AYLEN JÁUREGUI 1, B, ALDO MADEO ${ }^{1,8}$, SILVINA GYGLI, B, CLOE MARIN ${ }^{1, E, ~ F, ~ L A U R A ~ S O I B E L Z O N ~}{ }^{1,8}$, \\ EDUARDO MARTINEZ 1 , B, PATRICIA RIVADULLA ${ }^{1,0}$, MARIA RAFFAELI ${ }^{1, B}$, DANIELA SBATELLA ${ }^{1, F}$, \\ JORGE AGUEDA ${ }^{1, \mathrm{~B}}$, GRISELDA HAAG ${ }^{1, \mathrm{~B}}$, RICARDO WRIGHT ${ }^{1, \mathrm{D}, \mathrm{F}}$, ADRIANA ARINAVARRETA ${ }^{1, \mathrm{D}}$
}

${ }^{1}$ Faculty of Medicine, National University of La Plata, La Plata, Argentina

${ }^{2}$ CONICET - National Scientific and Technical Research Council, La Plata, Argentina

A - Study Design, B - Data Collection, C - Statistical Analysis, D - Data Interpretation, E - Manuscript Preparation, F - Literature Search, G - Funds Collection

Summary Background. Knowing how health problems are perceived is an element of primary importance for health systems, since it is the first step for the population to recognize a disease and demand medical attention.

Objectives. To develop and evaluate the implementation of a new healthcare model adapted to the necessities and illness self-perception of a community in the urban area of Greater La Plata, Buenos Aires, Argentina.

Material and methods. The community's self-rated general health status and illness self-perception were explored by a survey, followed by an intervention study performed on 2,430 participants randomly divided in 2 groups (Intervention: received personalized home health care; Control: health care was provided from hospitals and primary care health services).

Results. Almost $70 \%$ of the participants were satisfied with their health status. In cases where a disease was detected; older people and men shown to perceive their illness later compared to women and young adults. Only $21 \%$ of the population had suitable access to a health service. Compared with the Control Group, regular and personalized home visits significantly improved treatment adherence (43\% vs $94 \%)$, reduced annual undesirable events (stroke, myocardial infarcts, etc.) associated to chronic diseases $(2.7 \%$ vs $1.2 \%)$ and lowered hospitalization rates $(2.9 \%$ vs $2.0 \%)$

Conclusions. The data obtained showed that the population had low illness awareness, which reduced the spontaneous demand of care in health services. A model of health care based on regular home visits demonstrated efficacy in terms of disease prevention, illness control, avoiding consequences of chronic disease and reducing hospitalizations.

Key words: health services needs and demand, disease, awareness, delivery of health care, needs assessment.

Marin GH, Vetere P, Marin L, Giangreco L, Garcia G, Marin G, Alconada-Magliano J, Ferrero ML, Bourgeois M, Madonia MG, Moran V Jáuregui A, Madeo A, Gygli S, Marin C, Soibelzon L, Martinez E, Rivadulla P, Raffaeli M, Sbatella D, Agueda J, Haag G, Wright R, Arinavarreta A. Disease awareness as a barrier to health service admittance. An alternative healthcare model based on population needs. Fam Med Prim Care Rev 2021; 23(4): 452-458, doi: https://doi.org/10.5114/fmpcr.2021.110360.

\section{Background}

Self-rated general health status and awareness of illness might be influenced by many circumstances, personal situations or people's background [1]. The concept of "disease" is a cultural construction of each individual with respect to its own binomial health/disease status, as well as due to situations coming from the environment which can modify this relationship. Physical, emotional and social conditions are certainly important, not only in the etiology of a disease but also in people's illness awareness [2].

"Health" was defined by the World Health Organization (WHO) as "the complete physical, mental and social well-being state and not just the absence of disease or disability". It seems according to this definition that optimal health status is comparable to a complete, pleasant life without physical, mental or social problems, which is almost impossible to reach by anyone. However, it is well known that, in our world, inequalities, unfair differences, contrasting levels of opportunities to get a job, decent housing or access to essential goods such as basic services, drinking water, exist, which are aspects that finally translate into health problems. Authors like Floreal Ferrara [3] defined health "as the ability to face and overcome the conflicts and adversities that the environment presents us", which could be a more realistic definition. Unfortunately, people often internalize the unfavorable situations that they have had in life since birth, associating them with "normality". This characteristic reduces their ability to perceive health risks ("...at homes where all members have cough; cough is not considered a symptom/ sign of disease..."). This scenario ends with people having low illness perception abilities and limited capacities to detect a risk to their health. Consequently, lack of risk perception turns in low demand for health care.

Most of the health systems in the world are organized from the centrality of health institutions that provide health care only to those members of the community that demand attention [4].

Health system service utilization is then the result of a process that begins with the social, economic and cultural background that each person has, an aspect that affects people's own level of awareness and ability to perceive health problems, which later translates into a low demand for health care.

In other words, there are different levels of "illness" perception, since a diversity of meanings of "being healthy or sick" ex- 
ist, as well as different levels of importance attributed to some ailments. Hence, people's background and lifestyles influence the decision to demand care from the health system [5-7].

Except for the underaged pediatric population, very few people comply with regular health checks. Health institutions mostly take care of ill people that previously perceived symptoms and developed the will to ask for medical assistance [8]. It could be said then that current models of care require that patients go through several steps before access to health care.

\section{Objectives}

In order to know people's health/illness perception level in Gran La Plata, Buenos Aires, Argentina, to establish to what degree this perception influences the demand for care in the current health system, and what the impact of an alternative health care model based on people "needs" will be, we developed this study.

\section{Material and methods}

\section{Study design}

This is an "intervention study" with a control group, preceded by an initial descriptive cross-sectional stage destined to establish people's self-rated general health status and illness perception.

\section{Participants}

Participants were inhabitants of La Plata that were voluntarily recruited in a door-to-door home visit. 790 advanced medical students ( 684 for the diagnosis of health situation and 106 for the intervention stage) and 36 teachers participated in the study.

The inclusion criteria of participants were: $(A)$ to be over 18 years of age, (B) to understand either the issues raised to give informed consent or the items from the questionnaire, (C) a maximum of 2 adults surveyed for each household.

\section{Sample size}

Sample size was calculated using a G*power version 3.1 program; demanding a pilot group of participants to test predictor variables, a type I error of 0.05 , considering a power of 0.95 , and an effect size of 0.15 . According to these results, we decided to collect a minimum of 1,000 participants in each group, considering a $10 \%$ dropout rate.

\section{Methods}

After the enrollment of participants, students received special training to perform the survey and house visits, including basic medical examination of family members. Professors monitored the household surveys, verified the compliance of activities and defined the project operational guidelines.

Once "basal diagnosis" was performed (survey + basic medical exam, including weight and height measurement, blood pressure control, glycaemia test strips with automatic reader Accu-chek (Roche) ${ }^{\circledR}$, among other tests), the neighborhood was randomly divided in two areas: one was designed as the control group, in which home members had access to free, regular health care provided by public institutions, and an area for the intervention group, in whom members were provided regular home visits (minimum 2 per month) to each of the household surveyed.

The strategy for these visits consisted in assigning to each home and the members of that family a person "responsible" for their periodical health controls and their follow up, including treatment assurance and drug dispensing in case one or more members of the family had a chronic disease. This "responsible" person was an advance medical student.

A university professor medical doctor was in charge of monitoring the health care activities developed by each group of students. Students and their teachers visited their assigned homes during the 12-month period of the experience; in order to carry out a periodic routine medical examination to the members of the household, laboratories test, clinical practices and preventive tests related to the early detection of cancer (like Papanicolaou (PAP), blood stool for detection of colorectal cancer, mammography, prostate control). When a chronic disease was detected (like hypertension, diabetes, others), the visit also included benefits provided by provincial (PRODIABA, HTA, HIV) and national (Remediar) programs in order to guarantee medical service, free medicines, etc. Even when patients needed to be hospitalized, the students/professors made contact with the formal health system in order to follow up each case.

After one year, a new survey similar to the one done in basal situational diagnosis was performed on either the control or intervention group members.

\section{Variables}

The variables considered for the "Situational Diagnosis" stage were: Gender (SEX); Socio-economic structural conditions - basic need unsatisfied (BNU); Financial Situation \& Income Level (FISIT); Highest Educational Level Achieved (HELA); Employment Status (ESTAT); Insurance Status (IS); Marital Status (MASTAT); Living Arrangements (LA); Perceived Health Status (PHS); Disease Perception (DP); Healthcare Seeking Behavior (HCB) facing a symptom or a health problem, Distance to Health Institution (DHI) - distance from the home of the respondents to a healthcare center.

Variables considered for the "Intervention" stage were: presence or absent of a chronic disease; type of chronic disease; preventive practice performed; medicines needed for those diseases; adherence to treatments prescribed; complications associated with chronic disease; hospitalization rate.

\section{Operational definitions of variables}

For Gender (SEX): either female or male; Socio-economic structural conditions - basic need unsatisfied (BNU) expressed by one of these five concepts: Precarious housing; Sanitary deficiencies (households that do not have a toilet); Overcrowding conditions (more than three inhabitants per room); School non-attendance (households that have at least one school-age child (6 to 12 years old) who does not attend school); Subsistence capacity (includes households that have four or more people per employed member and that have a head who has not completed the third grade of primary schooling); Financial Situation \& Income Level (FISIT): to determine this variable, it was established whether the family income of the household reaches the total cost of all essential resources (basic basket of goods and services); Highest Educational Level Achieved (HELA): this item establishes the maximum educational level reached by the respondent and is classified into three categories: Basic Education, High School and University-Tertiary; Employment status (ESTAT): categorized by employed or unemployed status; Insurance Status (IS): if responder has health coverage at the time of survey performance; Marital status (MASTAT); Married/or couple, Single, Separated/Divorced; Living arrangements (LA): with whom the responder lives. Options were "only as a couple", "alone" (solitary), "with children or relatives"; Perceived Health Status (PHS): categorized by six levels on how the respondent rates their own health: very bad, bad, fair, good, very good, excellent; Disease Perception (DP): this item measures the degree if the respondent perceives a symptom or manifest disease (Yes or No); Distance to Health Institution (DHI): the average distance from the home of the respondents to a health 
center (measured in kilometers); Healthcare Seeking Behavior (HSB): classified as appropriate or inappropriate. Appropriate HSB was defined by consulting a qualified medical professional or seeking health care at orthodox health facilities, such as primary health centers, general public hospitals or private health institutions, during illness episodes or any situation requiring medical attention. Inappropriate HSB comprises doing nothing at all when signs or symptoms were perceived or consulting with a friend, neighbors or family members [9]. Medicines for chronic disease: were obtained from each one of the drugs prescribed to patients for their chronic disease; Adherence to treatments prescribed: considered as continuity in the access the medicine and consumption; Complications associated to chronic disease: presence of stroke, Ccardiac infarcts, renal disease, retinopathies; Hospitalization: as a dichotomous answer to whether the patient was hospitalized or not (Yes or No) (length of stay was also registered).

\section{Instrument for data collection}

The Illness Perception Questionnaire (IPQ) [10, 11] was adapted in order to measure health status and illness. Perceived health status was assessed using a 3-item questionnaire with possible scores ranging from 1 (very bad) to 5 (very good). The higher the average score of the 3 items, the better the perceived health status. The list of domains assessed by this instrument includes components related to coherence, concern, consequences, control (personal and treatment), emotional representation, identity and timeline (acute/chronic and cyclical), which were represented by the variables selected for this study. These components provided a framework for patients about symptoms awareness, assessment of health risk and individual's coherent view of an illness [12-14]. A number of additional questions were included in the survey in order to detect 10 particular groups of illnesses related to cardiovascular diseases, type- 2 diabetes, renal disease, asthma, osteoarticular disease, mental health diseases, endocrine pathologies, infectious diseases, gastrointestinal diseases or minor illnesses (allergies, colds, headaches).

Data was collected from a survey performed at the end of the study (after 12 months) and was also obtained during the follow up period in the intervention group, where data was extracted from home visits, from the data source from Primary Health Care Units (CAPS) of La Plata, as well as data provided by 5 hospitals located in the geographical area of Gran La Plata, Buenos Aires, Argentina. Information about medicines and medical practices was obtained from the REMEDIAR, PRODIABA, PROEPI and State programs.

\section{Ethical aspects}

The CIC-PBA Ethics Committee approved the study protocol.

\section{Statistical analyses}

Descriptive statistics were used to define the general characteristics and variables using the SPSS version 24 program. Pearson's correlation analysis was performed for perceived health status, occupational stress, sleep quality and motives for food choices. Step-wise multiple regression analyses were used to examine factors influencing perceived health status. The multivariate linear regression was adjusted for general characteristics such as age, gender, level of education, living arrangements and the number of illnesses. Student's test was used to compare data obtained from patients belonging to the intervention and control groups. Statistical significance was set at a $p$-value of $<0.05$.

\section{Results}

\section{Basal situational diagnosis}

2,430 participants were enrolled in the study. Their mean age was $54.7 \pm 23.4$ years $(59.3 \%$ were female). The socio-economic situation of the $36.5 \%$ of families living in homes enrolled in the study had structural poverty; $36.4 \%$ lived below the "economic poverty line" (since their incomes did not achieve the basic basket of goods and services), and $11.6 \%$ were classified as "indigent" as their monthly home salaries were below shopping basket. The average distance from the home surveyed to a health center was $1.12 \pm 2.9 \mathrm{~km}$.

Concerning the participants' habits, $27.6 \%$ declared smoking at least 3 cigarettes per day (10.3 \pm 9.5 cigarettes/day in average), and $21.3 \%$ consumed at least 20 grams per day or 140 grams per week of alcohol.

At the time of visiting the homes, $16.5 \% \pm 0.39$ of the respondents were overweight, $35.1 \% \pm 0.49$ were overweight, and $48.4 \% \pm 0.57$ had normal weight; while hypertension was detected in $39.6 \%$ of the cases, and $19.3 \%$ had abnormal blood glucose levels, although only in $12.4 \%$ of the cases was diabetes confirmed with a glucose tolerance test performed in subsequent medical consultations.

Participants self-rated their own general health status, expressing in $22.3 \%$ of the cases that their health status was very good or excellent, $49.6 \%$ good, and in $28.1 \%$ of the cases, the status was considered fair, bad or very bad. The only variable that had statistical significance in relation to health status perception was gender, since $74.51 \%$ of the males considered themselves in optimal health status, while among females, this level was lower (66.8\%) $p=0.003$ (Tab. 1).

Disease perception was mainly associated with two variables: gender (since female's awareness was higher than males $(44.7 \%$ vs $30.2 \%)$ and socio-economic structural conditions (less perception in people with BNU (31.9\% vs $43.9 \%) p=0.01$. No statistical differences were observed between the control or intervention groups for each one of the "perception" variables.

\begin{tabular}{|c|c|c|c|c|c|c|c|c|}
\hline \multirow[t]{2}{*}{ Variables } & \multicolumn{2}{|c|}{ Perceived health status (PHS)* } & \multicolumn{2}{|c|}{$\begin{array}{l}\text { Disease perception } \\
\text { (DP**) }\end{array}$} & \multirow{2}{*}{$\begin{array}{l}\text { Inappropri- } \\
\text { ate HSB } \\
78.5 \% \\
(n=723) \\
\end{array}$} & \multirow{2}{*}{$\begin{array}{l}\text { Appropriate } \\
\text { HSB } \\
21.5 \% \\
(n=198) \\
\end{array}$} & \multirow[t]{2}{*}{$x^{2}$} & \multirow[t]{2}{*}{$p$} \\
\hline & $\begin{array}{l}\text { E-VG-G } \\
(n=1747)\end{array}$ & \begin{tabular}{|l|} 
F-B-VB \\
$(n=683)$
\end{tabular} & $\begin{array}{l}\text { Yes } \\
(n=414)\end{array}$ & $\begin{array}{l}\text { No } \\
(n=507)\end{array}$ & & & & \\
\hline \multicolumn{9}{|c|}{ Age (years) } \\
\hline$\leq 29$ & $256(82.0 \%)$ & $56(18.0 \%)$ & $59(43.4 \%)$ & $77(56.6 \%)$ & $170(23.5 \%)$ & $48(24.3 \%)$ & \multirow[t]{4}{*}{1.75} & \multirow[t]{4}{*}{0.59} \\
\hline $30-49$ & $655(72.0 \%)$ & $255(28.0 \%)$ & $155(44.4 \%)$ & $194(55.6 \%)$ & $260(35.9 \%)$ & $72(35.9)$ & & \\
\hline $50-64$ & $511(68.2 \%)$ & $238(31.8 \%)$ & $118(45.6 \%)$ & $140(54.4 \%)$ & $204(28.2 \%)$ & $53(26.3 \%)$ & & \\
\hline$\geq 65$ & $299(65.2 \%)$ & $72(23.0 \%)$ & $82(46.1 \%)$ & $96(53.9 \%)$ & $89(12.3 \%)$ & $25(12.2 \%)$ & & \\
\hline \multicolumn{9}{|l|}{ Gender } \\
\hline Female & $963(66.8 \%)$ & 478 (33.2\%) & $244(44.7 \%)$ & $302(55.3 \%)$ & $541(74.8 \%)$ & $148(74.7 \%)$ & \multirow[t]{2}{*}{0.05} & \multirow[t]{2}{*}{0.93} \\
\hline Male & $737(74.5 \%)$ & $252(25.5 \%)$ & $113(30.2 \%)$ & $262(69.8 \%)$ & $182(25.2 \%)$ & 50 (25.3\%) & & \\
\hline
\end{tabular}




\begin{tabular}{|c|c|c|c|c|c|c|c|c|}
\hline \multirow[t]{2}{*}{ Variables } & \multicolumn{2}{|c|}{ Perceived health status (PHS)* } & \multicolumn{2}{|c|}{$\begin{array}{l}\text { Disease perception } \\
\text { (DP**) }\end{array}$} & \multirow{2}{*}{\begin{tabular}{|l} 
Inappropri- \\
ate HSB \\
$78.5 \%$ \\
$(n=723)$ \\
\end{tabular}} & \multirow{2}{*}{\begin{tabular}{|l|}
$\begin{array}{l}\text { Appropriate } \\
\text { HSB }\end{array}$ \\
$21.5 \%$ \\
$(n=198)$
\end{tabular}} & \multirow[t]{2}{*}{$x^{2}$} & \multirow[t]{2}{*}{$p$} \\
\hline & $\begin{array}{l}\text { E-VG-G } \\
(n=1747)\end{array}$ & $\begin{array}{l}\text { F-B-VB } \\
(n=683)\end{array}$ & $\begin{array}{l}\text { Yes } \\
(n=414)\end{array}$ & $\begin{array}{l}\text { No } \\
(n=507)\end{array}$ & & & & \\
\hline \multicolumn{9}{|l|}{ Marital status } \\
\hline Married or a couple & $1,026(73.2 \%)$ & $375(26.8 \%)$ & $241(44.3 \%)$ & $313(55.6 \%)$ & 401 (56.1\%) & $105(52.5 \%)$ & \multirow[t]{4}{*}{0.38} & \multirow[t]{4}{*}{0.54} \\
\hline Single & $222(70.5 \%)$ & $93(29.5 \%)$ & $54(43.5 \%)$ & $70(56.5 \%)$ & $108(15.0 \%)$ & $19(9.5 \%)$ & & \\
\hline Separated/divorced & $368(72.1 \%)$ & $143(27.9 \%)$ & $96(46.7 \%)$ & $109(53.3 \%)$ & $154(21.2 \%)$ & $61(30.7 \%)$ & & \\
\hline Widowed & 145 (71.5\%) & $58(28.5 \%)$ & $22(45.2 \%)$ & $26(54.8 \%)$ & $55(7.7 \%)$ & $13(6.3 \%)$ & & \\
\hline \multicolumn{9}{|c|}{ Living arrangements $n(\%)$} \\
\hline With couple & $354(72.7 \%)$ & $133(27.3 \%)$ & $88(45.3 \%)$ & $106(54.7 \%)$ & $366(50.6 \%)$ & $104(52.5 \%)$ & \multirow[t]{3}{*}{0.45} & \multirow[t]{3}{*}{0.62} \\
\hline Solitary & $222(70.8 \%)$ & $92(29.2)$ & $42(44.7 \%)$ & $52(55.3 \%)$ & $92(12.7 \%)$ & $32(16.1 \%)$ & & \\
\hline With children/relatives & $1,176(72.2 \%)$ & $453(27.8)$ & $285(45.0 \%)$ & $348(55.0 \%)$ & $265(36.6 \%)$ & $62(31.3 \%)$ & & \\
\hline \multicolumn{9}{|c|}{ Higher level of education achieved } \\
\hline $\begin{array}{l}\text { Elementary school or } \\
\text { lower }\end{array}$ & 440 (72.9\%) & $164(27.1 \%)$ & 107 (43.5\%) & $140(56.5 \%)$ & $306(42.2 \%)$ & $40(20.3 \%)$ & \multirow[t]{3}{*}{40.4} & \multirow[t]{3}{*}{$<0.01$} \\
\hline High school & $1,030(71.7 \%)$ & 407 (28.3\%) & $243(45.1 \%)$ & $295(54.9 \%)$ & 349 (48.2\%) & $51(25.6 \%)$ & & \\
\hline University/Tertiary & $276(70.9 \%)$ & $114(29.1 \%)$ & $63(46.2 \%)$ & $73(53.8 \%)$ & $68(9.4 \%)$ & 107 (54.1\%) & & \\
\hline \multicolumn{9}{|c|}{ Income (economic status) level } \\
\hline Upper & 146 (73.3\%) & $53(26.7 \%)$ & $33(46.9 \%)$ & $38(53.1 \%)$ & 67 (9.3\%) & $26(13.1 \%)$ & \multirow[t]{3}{*}{37.5} & \multirow[t]{3}{*}{$<0.01$} \\
\hline Middle & $962(71.5 \%)$ & $384(28.5 \%)$ & $202(44.2 \%)$ & $254(55.8 \%)$ & 397 (54.9\%) & $103(52.0 \%)$ & & \\
\hline Lower & $626(70.8 \%)$ & $259(29.2 \%)$ & $171(43.5 \%)$ & $223(56.5 \%)$ & $259(35.8 \%)$ & $69(34.9 \%)$ & & \\
\hline \multicolumn{9}{|c|}{ Social condition (structural) BNU } \\
\hline BNU yes & $637(72.2 \%)$ & $245(27.8 \%)$ & $110(31.9 \%)$ & $234(68.1 \%)$ & $436(60.3 \%)$ & $68(34.2 \%)$ & \multirow[t]{2}{*}{36} & \multirow[t]{2}{*}{$<0.01$} \\
\hline BNU no & $1,108(71.6 \%)$ & $440(28.4 \%)$ & $253(43.9 \%)$ & $324(56.1 \%)$ & $287(39.7 \%)$ & $130(60.1 \%)$ & & \\
\hline \multicolumn{9}{|l|}{ Employment status } \\
\hline Employed & $1,137(70.8 \%)$ & $469(29.2 \%)$ & $282(45.8 \%)$ & $333(54.2 \%)$ & $426(58.9 \%)$ & $119(60.1 \%)$ & \multirow[t]{3}{*}{21.75} & \multirow[t]{3}{*}{0.06} \\
\hline Unemployed & $408(70.5 \%)$ & $171(29.5 \%)$ & $102(44.2 \%)$ & $128(55.8 \%)$ & $260(35.9 \%)$ & $72(36.3 \%)$ & & \\
\hline Retired & $182(74.4 \%)$ & $63(25.6 \%)$ & $34(44.8 \%)$ & $42(55.2 \%)$ & $37(5.2 \%)$ & $7(3.6 \%)$ & & \\
\hline \multicolumn{9}{|l|}{ Insurance status } \\
\hline Insured & $891(72.3 \%)$ & $341(27.7 \%)$ & $207(45.6 \%)$ & $247(54.4 \%)$ & $220(30.4 \%)$ & $125(63.1 \%)$ & \multirow[t]{2}{*}{36} & \multirow[t]{2}{*}{0.01} \\
\hline Uninsured & $858(71.6 \%)$ & $340(28.4 \%)$ & $206(44.2 \%)$ & $261(55.8 \%)$ & $503(69.6 \%)$ & $73(36.9 \%)$ & & \\
\hline \multicolumn{9}{|c|}{ Distance to health institution } \\
\hline$<2 \mathrm{~km}$ & $745(71.7 \%)$ & $295(28.3 \%)$ & $187(45.3 \%)$ & $226(54.7 \%)$ & $295(40.8 \%)$ & $79(39.9 \%)$ & 0.30 & 0.78 \\
\hline$>2 \mathrm{~km}$ & $1,005(72.3 \%)$ & $385(26.7 \%)$ & $227(44.7 \%)$ & $281(55.3 \%)$ & $428(59.2 \%)$ & $119(60.1 \%)$ & & \\
\hline
\end{tabular}

PHS - Perceived health status - categorized by 6 levels on how the respondent rates their own health: (VB) very bad, (B) bad, (F) fair, (G) good, (VG) very good, (E) excellent; DP - Disease perception - measures whether respondents perceived a symptom or disease; ${ }^{*}$ Data extracted from 2,430 participants; **Data extracted from 921 participants that had a health problem during the last 15 days; $p$ - $p$-value, statistical significance level alpha was considered from $p$-values $<0.05$.

From the survey and physical examination, disease was detected in 921 of the 2,430 participants. However, only 414 of them (44.9\%) perceived the health problem. Finally; only 198 patients in whom a health problem was detected (21.5\%) had an adequate behavior consulting a health service (Table 1). Among the participants that did not demand health care even after perceiving an illness, the main reasons given to bypass consultation was because they already self-medicated $(26.2 \%)$, they wanted to avoid leaving the children alone $(23.1 \%)$, they lacked time $(14.2 \%)$, they did not consider that medical consultation was important (12.9\%), lack of money (3.1\%), they took into account losing hours at their jobs (10.2\%), or they considered the administrative procedures complex (10.3\%).

The health problems detected in basal situation diagnosis among participants were cold or flu problems $(40.2 \%)$, pain or osteoarticular problems (19.4\%), discomfort or gastrointestinal pain $(11.3 \%)$, headache $(9.7 \%)$, dizziness or vertigo $(8.5 \%)$, while in $10.9 \%$ of the cases, other health problems were identify.

$87.6 \%$ of insured participants obtained health care from the private sector, while $46.6 \%$ of those not insured also chose private institutions. $43.5 \%$ of the participants reported one or more chronic disease (mean for number of illness $1.2 \pm 1.14$ ).

The most frequent mental health problem observed was depression (363 of the participants); however, only 114 patients (31.4\%) went for consultation for this reason.
Disability was detected in $4.4 \%$ of the participants.

$20.3 \%$ of the participants suffered a situation of violence during the study (46.1\% physical violence and $53.9 \%$ verbal violence). These episodes mainly occurred inside the family environment $(34.6 \%)$, at work $(10.0 \%)$ or in the street $(52.3 \%)$. The gender of the victim was mostly female $(88.2 \%)$, while the gender of the aggressor was mainly male (83.2\%).

Regarding the place in which the participants received the last health care, $20.2 \%$ responded in a public hospital, $11.6 \%$ in a primary healthcare Center, $49.7 \%$ in a private hospital, $17.1 \%$ in a health office, $1.1 \%$ at work and $0.3 \%$ at home.

Concerning medicine consumption, 1,702 participants consumed at least 1 drug, while $7.4 \%$ of them consumed 2 or more medicines. The therapeutic groups were: antihypertensive (31.1\%), antibiotics (12.7\%), analgesics (38.7\%), antidiabetics $(15.6 \%)$, antispasmodics $(1 \%)$, corticosteroids $(4.2 \%)$, contraceptives $(32.8 \%)$, sedatives $(4.2 \%)$, vitamins $(4.7 \%)$, expectorants $(1 \%)$, others $(28.8 \%)$. $78.4 \%$ of the patients had to make a partial or total payment for the drugs consumed.

\section{Data extracted from the intervention and control groups}

In basal situational diagnosis, participants belonging to the control or intervention groups demonstrated non-significant 


\begin{tabular}{|c|c|c|c|c|c|c|}
\hline \multirow{2}{*}{$\begin{array}{l}\text { Partici- } \\
\text { pant }\end{array}$} & \multirow[t]{2}{*}{ Variable } & \multicolumn{2}{|c|}{ CG $(n=1426)$} & \multicolumn{2}{|c|}{ IG $(n=1004)$} & \multirow{2}{*}{$\frac{p}{\text { value }}$} \\
\hline & & baseline & post & baseline & post & \\
\hline \multirow{6}{*}{ 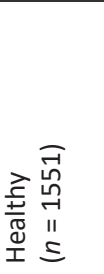 } & PAP test (only females) (\%) & 38.3 & 38.7 & 38.5 & 73.2 & 0.006 \\
\hline & Blood stool test (all > 50 yrs) (\%) & 0.3 & 0.3 & 0.3 & 68.5 & $<0.0001$ \\
\hline & Mammography (females > 50 yrs) (\%) & 20.1 & 21.3 & 20.2 & 42.8 & 0.02 \\
\hline & Prostate controls (male > 50 yrs) (\%) & 2.9 & 2.1 & 2.7 & 31.3 & $<0.0001$ \\
\hline & Smoking habit & 27.1 & 27.6 & 27.0 & 7.4 & 0.001 \\
\hline & Violence (family events) & 19.8 & 19.6 & 20.1 & 6.8 & 0.001 \\
\hline \multirow{7}{*}{ 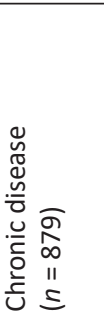 } & Treatment adherence (\%) & 43.6 & 44.1 & 43.2 & 94.1 & 0.01 \\
\hline & $\mathrm{HbA}_{1 \mathrm{c}}$ blood levels (only DBT) (\%) & 7.2 & 7.0 & 7.4 & 6.1 & 0.02 \\
\hline & Mean arterial blood pressure & $120.8 \pm 4.5$ & $120.1 \pm 3.4$ & $121.0 \pm 4.2$ & $99.1 \pm 5.1$ & 0.01 \\
\hline & Strokes events & - & 1.1 & - & 0.3 & 0.01 \\
\hline & Cardiovascular events & - & 2.9 & - & 1.3 & 0.03 \\
\hline & Hyperglycemia crisis events & - & 4.3 & - & 2.0 & 0.5 \\
\hline & Hospitalization & - & 3.9 & - & 2.2 & 0.01 \\
\hline
\end{tabular}

IG - Intervention Group; CG - Control Group; PAP - Papanicolaou test; Baseline - Initial data obtained from first visit to the household; Post - data obtained at the household visit; $p$-statistical significance level alpha was considered from $p$-values $<0.05$.

differences regarding main variables. Age, gender, smoking status, dyslipidemias, BMI or cardiovascular risk scores and other general variables were similar for both groups. These similarities found for the intervention and control geographical areas can be explained because both groups belong to the same town and share the same cultural, socio-economic features and population roots.

The similarity found for the intervention and control population can be explained because both groups belong to the same municipality and share cultural roots, socio-economic and population distribution aspects.

Intervention activities consisted in a weekly home visits (on Saturdays), performed by professor-student binomial teams, in order to warrant development of routine health controls, laboratory test and, in case of chronic diseases, a weekly treatment delivery to guarantee continuity in therapeutic guidelines.

After twelve months, a new situational diagnosis was performed either in the control or intervention groups' homes. The data demonstrated that healthy people belonging to the intervention group had 4 times more PAP tests performed, had 6 times more blood stool tests, had 3 times more mammography done, and 8 times more prostate controls compared to participants from the control group (Table 2).

Comparing patients with chronic disease belonging to the control vs intervention group, we observed that regular programmed consultation was only seen in $30.1 \%$ of participants from the control group and $100 \%$ of those from the intervention group.

After 12 months, treatment adherence of was $43.6 \%$ (even less if receiving two drugs $30.5 \%$ ) in "Control" participants, and $94.1 \%(81.2 \%$ if treated with two drugs) in participants belonging to "Intervention" group $(p<0.001)$ (Table 2). Dose omissions represented the most prevalent form of non-adherence; while overdose and dropout were the $2^{\text {nd }}$ causes.

In patients belonging to the intervention group, in which their chronic disease was diabetes, it was noted that $\mathrm{HbA}_{1 \mathrm{c}}$ blood levels were improved when compared with either their own baseline (7.4 vs $6.1 ; p=0.001$ ) or with patients from the control group ( 7.2 baseline vs 7.0 after 12 months; $p>0.05$ ).

In patients with arterial hypertension, among patients from the control group, no significant changes in their mean arterial blood pressure was seen $(120.8 \pm 4.5 \mathrm{~mm} \mathrm{Hg}$ in baseline registration, and $120.1 \pm 3.4 \mathrm{~mm} \mathrm{Hg}$ at the control visit after 12 months). However, patients from the intervention group showed a substantial reduction of their mean arterial blood pressure after one year of follow-up $(121.0 \pm 4.2 \mathrm{~mm} \mathrm{Hg}$ baseline vs $98.1 \pm 5.1 \mathrm{~mm} \mathrm{Hg}$ after 12 months; $p<0.001$ ) (Table 2 ).
Concerning events due to complications associated to chronic diseases, benefits were seen for the intervention group in terms of reduction of strokes, coronary events, hyperglycemia crisis, though not in renal, ophthalmological or neuronal events. Strokes were seen in $1.1 \%$ among patients belonging to the control group and in $0.3 \%$ of the intervention group; coronary events were seen in $2.9 \%$ vs $1.3 \%$, respectively; while uncontrolled glycaemia events were seen in $4.3 \%$ patients from the control group compared with $2.0 \%$ of the intervention group.

Concerning hospitalization, the overall rate was $2.9 \%$ and $2.0 \%$ for the control and intervention groups, respectively. However, among patients with chronic diseases, it was registered that $3.9 \%$ of patients from the control group required admittance to the health institution, while the percentage in patients from the intervention group was $2.6 \%$. The length of stay at hospital was $7.7 \pm 5.3$ days and $7.4 \pm 6.1$ days for the control an intervention groups.

\section{Discussion}

Self-assessment of health status and perception of illness is influenced by people's values, representations, roles and expectations that people have about the "health-disease process" [15].

People tend to think that they have good health condition when they have a lack of disease, signs or symptoms. This "healthy" feeling is associated with a low level of health controls, and low preventive care actions rates [16].

This point can also be observed in the data obtained from our study, which is a continuance of previous works performed by our team $[17,18]$. In our results, only $44.9 \%$ of participants who perceived symptoms, signs or in whom disease was detected recognized themselves as "ill". Only in $21.5 \%$ of the population in which any disease was detected; a spontaneous request for health care by these inhabitants in the health system was verified.

Our data also demonstrated that older people and women perceived their own health status worse than men; however, males overestimated their health level. This situation might explain why men belatedly consulted the health system, even when they perceived a disease. Hence, once signs or symptoms were perceived, HSB (in terms of prompt medical consultation) was better in females, in people with a higher level of education, in those inhabitants with health insurance or with better socio-economic conditions.

This situation should make us reflect about the existence of severe inequities in health systems, as well as that not all citi- 
zens have the same opportunities to access to health system. Classical "healthcare models" require that people first perceive their illness, which then depends on people's willing to seek consultation, and afterwards, it depends on the individual's demand for health care $[15,16]$. These preconditions threaten the fulfillment of health system's functions, as it affects their main goals, e.g. maintaining the population in good health status, preventing diseases, illness detection, damage limitation and disability rehabilitation $[17,18]$.

That is why one of the limitations of this type of study is the selection bias, since the results might vary widely according to the population considered in the study. In order to avoid this problem, the selection bias was intended to be reduced by limiting enquiries and the intervention to an urban area which represents all social, cultural and economic stratus of the local society. Even the intervention stage was performed in the same area where homes were chosen respecting the proportionality of these elements based in the National Statistical Institute data (INDEC). Another limitation of the study was a bias of gender in the initial survey's responders, since the majority were female and they remain at home more often and in greater number than males. This data was considered in the sample estimation [19].

The results obtained from the intervention group might be the most interesting of our work, since it demonstrated that a regular visit performed by health system staff (or its equivalent, e.g. university students), raised the level of preventive controls in healthy people (4 times more PAP tests performed, 6 times more colorectal cancer tests done, 3 times more mammography achieved, and 8 times more prostate control carried out. Among people with chronic disease, the actions carried out among the members of the "Intervention Group" were able to significantly increase the rate of health check-ups, reduce com- plications associated with chronic diseases, triple adherence to treatment, and reduce the rate of hospitalization, in comparison with patients belonging to the control group.

The intervention experience performed in this work may offer the basis to develop an alternative model of care centralized in people's homes and on their needs instead of current systems that focus on health institutions and require people's perception of illness and their willing to demand healthcare services.

\section{Conclusions}

The perception of diseases in the population studied was low on average and dependent on gender, socio-economic conditions and educational level. Inadequate and limited behavior in seeking professional help, as well as late visits to health services, were observed in the general population and, to a greater extent, in specific groups.

This data and the results obtained from the intervention experience led us to propose an alternative model of health care capable of including all members of society, regardless of whether or not they perceive their disease. This model was well applied in healthy people (who needed preventive actions to keep their health in good condition), as well as in those who were already sick and needed disease control and continuity in their treatments.

Compared with the classic health model, the results obtained with the alternative model showed an exponential increase in preventive practices and a significant difference in terms of optimization of disease control, reduction of disease complications, increased adherence to treatment and decreased hospitalization rates.

Source of funding: This work was funded by the National University of La Plata and CONICET - National Scientific and Technical Research Council.

Conflicts of interest: The authors declare no conflicts of interest.

\section{References}

1. Vega-Franco L. Ideas, beliefs and perceptions about health. Historical review. Salud Publica Mex 2002; 44(3): 258-265.

2. Sigerist HE. Health. J Public Health Pol 1996; 17: 204-234.

3. Ferrara FA. Political theory and health. Vol. 2. Addressing health. Buenos Aires: Catalogs; 1993.

4. Marin GH, Marin L, Errecalde J. Impact in the reduction of complications through a personalized follow-up strategy to ensure adherence to antihypertensive therapy. IJASET 2019; 7(4): 9-11.

5. Kornblit AL, Mendes Diz AM. Health and disease: biological and social aspects. Buenos Aires: Ed. Aique; 2000.

6. Gómez López L, Rabanaque Hernández MJ. Health concept. In: Colomer Revuelta C, Álvarez-Dardet C, eds. Health promotion and social change. Barcelona: Ed. Masson; 2000: 27-45.

7. Llovet JJ. Health services and popular sectors: the years of the process. Buenos Aires: CEDES; 1984.

8. Menéndez E. [Models of disease care: theoretical exclusions and practical articulations]. In: Spinelli H, compilator. Salud Colectiva. Cultura, instituciones y subjetividad. Epidemiología, gestión y políticas. Buenos Aires: Lugar Editorial; 2004 (in Spanish).

9. MacKian S. A review of health seeking behaviour: problems and prospects. Manchester: University of Manchester; 2003. Available from URL: http://citeseerx.ist.psu.edu/viewdoc/download?doi=10.1.1.473.8350\&rep=rep1\&type=pdf.

10. Leventhal H, Benyamini Y, Brownlee S, et al. Illness representations: theoretical foundations. In: Petrie KJ, Weinman J, eds. Perceptions of health and illness: current research and applications. Amsterdam: Harwood Academic Publishers; 1997: 19-45.

11. Leventhal H, Leventhal EA, Cameron L. Representations, procedures, and affect in illness self-regulation: a perceptual-cognitive model. In: Baum A, Revenson TA, Singer JE, eds. Handbook of health psychology. Mahwah, New Jersey: Lawrence Erlbaum; 2001: 19-48.

12. Broadbent E, Petrie KJ, Main J, et al. The brief illness perception questionnaire. J Psychosom Res 2006; 60: 631-637.

13. Moss-Morris R, Weinman J, Petrie KJ, et al. The Revised Illness Perception Questionnaire (IPQ-R). Psychol Health 2002; 17 : 1-16.

14. Weinman J, Petrie KJ, Moss-Morris R, et al. The illness perception questionnaire: a new method for assessing the cognitive representation of illness. Psychol Health 1996; 11: 431-445

15. Marín GH, Rivadulla P, Vázquez A, et al. Interdisciplinary health project: a model based in home care makes the difference. An Sist Sanit Navar 2006; 29(1): 107-118, doi: 10.4321/s1137-66272006000100009. PMID: 16670733.

16. Marín G, Silberman M, Etchegoyen G. [A personalised health care programme (PANDELAS) operating in Buenos Aires, Argentina, during 2006]. Rev Salud Publica (Bogota). 2008; 10(2): 203-214, doi: 10.1590/s0124-00642008000200001 (in Spanish).

17. Marin GH. Vetere P, Marin L. et al. Barriers to health service access: a study on conditioning factors of self-health \& illness perception in Argentina. Advances Applied Sociology 2021; 11: 315-334.

18. Marin GH, Silberman M, Colombo MV, et al. Manager's leadership is the main skill for ambulatory health care plan success. $J$ Ambul Care Manage 2015; 38(1): 59-68, doi: 10.1097/jac.0000000000000014.

19. Xie Y. Population heterogeneity and causal inference. PNAS 2013; 110(16): 6262-6268, doi: 10.1073/pnas.1303102110 
Tables: 2

Figures: 0

References: 19

Received: 23.05.2021

Reviewed: 28.05.2021

Accepted: 22.07.2021

Address for correspondence:

Prof. Gustavo H. Marin

Faculty of Medicine

National University of La Plata

CONICET - National Scientific and Technical Research Council

Calle 60\&120 - La Plata

Argentina

Tel.: +54 92215030058

E-mail: gmarin@med.unlp.edu.ar, gmarin2009@gmail.com 